\title{
High cytoplasmic expression of SALL4 predicts a malignant phenotype and poor prognosis of breast invasive ductal carcinoma
}

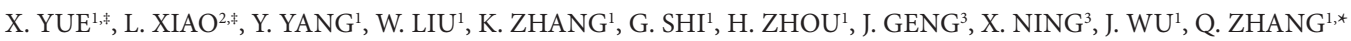 \\ ${ }^{1}$ Department of Medical Oncology, The Affiliated Tumor Hospital, Harbin Medical University, Harbin 150081, People's Republic of China; ${ }^{2}$ Depart- \\ ment of General Surgery, The Fourth Affiliated Hospital, Harbin Medical University, Harbin 150001, People's Republic of China; ${ }^{3}$ Department \\ of Pathology, The Affiliated Tumor Hospital, Harbin Medical University, Harbin 150081, People's Republic of China
}

*Correspondence: Zhangqyhmu@126.com

${ }^{*}$ Contributed equally to this work.

Received February 6, 2015 / Accepted July 13, 2015

\begin{abstract}
Sal-like 4(SALL4) is significant for maintaining self-renewal and pluripotency in embryonic stem cells, cancer cells and perhaps even cancer stem cells. The expression of SALL4 has been recorded in various kinds of cancers and is deemed to have a clinical value for diagnosis. However, little information on SALL4 expression has been illustrated in breast cancer. In this study, the expression of SALL4 was scrutinized by immunohistochemical analysis in breast invasive ductal carcinoma in a large cohort of 160 patients. High cytoplasmic expression of SALL4 was detected in breast cancer tissues compared with normal adjacent tissues. High SALL4 expression was associated with advanced tumor invasion $(\mathrm{p}=0.019)$, lymph node stage $(p=0.027)$, ER $(p=0.030)$, PR $(p=0.037)$, HER2 $(p=0.019)$ and TNBC $(p=0.007)$ in overall patients. Interestingly, in Kaplan-Meier analysis, breast cancer patients with high expression of SALL4 demonstrated a worse OS. Both univariate and multivariate analysis illustrated that examination of SALL4 was of great prognostic value in OS. Thus, our data showed that high cytoplasmic expression of SALL4 was considered to be an independent prognostic indicator for breast invasive ductal carcinoma.
\end{abstract}

Key words: breast cancer, SALL4, expressional analysis, immunohistochemical analysis, prognosis, biomarker

With at least 1.2 million new cases diagnosed and 500000 deaths every year, breast cancer is known as the most common cancer in women and takes the second place of the leading cause of cancer related death in women all around the world $[1,2]$. Being regarded as a high heterogeneousness disease, breast cancer always results in different outcomes, some cancers displaying a slow tumor growth and splendid prognosis whilst other tumors presenting a clinical course with high aggression [3]. Although surgery and chemotherapeutic/radiologic interference could be feasible options for early stage breast cancer patients, the outcome is nonetheless gloomy for patients in advanced stage. Despite the fact that the

\footnotetext{
Abbreviations: SALL4 - Sal-like 4; ER, estrogen receptor; PR - progesterone receptor; HER2 - human epidermal growth factor receptor 2; TNBC - triple-negative breast cancer; OS - overall survival; MDS - myelodysplastic syndrome; AJCC - American Joint Committee on Cancer; ROC - receiver operating characteristic
}

recognition of epidemiologic breast cancer risk factors have been enhanced, the prognostic value of most of acknowledged risk factors are still at low level. The current understanding of potential mechanisms of breast cancer, especially at molecular level, has proved inadequate to overcome the disease [4]. To enhance the therapeutic efficacy of breast cancer, it is imperative to understand profoundly the molecular pathogenesis of cancer cells as well as identify newer candidate genes/proteins which are crucial in the proliferating and metastatic process, are able to promote detection of tumor at high specificity and sensitivity rate and are possible to be recognized as newer treatment targets.

Sal-like 4(SALL4), encoding a C2H2 zinc-finger transcription factor, is the human homologue of the Drosophila spalt homeotic gene [5]. SALL4 is supposed to play a significant role in the maintenance of pluripotency and self-renewal of embryonic stem cells, cancer cells and perhaps even cancer stem cells [6-9]. It was the first time that SALL4 was described 
as an oncogene when its expression was examined in leukemia [10]. SALL4 was shown to be constitutively expressed in human acute myeloid leukemia [10]. SALL4B transgenic mice developed myelodysplastic syndrome (MDS) - like features and subsequently acute myeloid leukemia [10]. Consecutively, the expression of SALL4 has been recorded in varied kinds of cancers and is deemed to have a clinical value for diagnosis in a few of them, including germ cell tumor, aggressive hepatocellular carcinoma, colorectal cancer, gastric cancer and extragonadal yolk sac tumors [11-15]. However, the information on expression and prognostic value of SALL4 in breast cancer was quite limited $[16,17]$. More studies should be carried out to identify the exact role of SALL4 in the proliferation and even tumorigenesis of breast cancer. Hence, in this study, we aimed to investigate the prognostic value of SALL4 as a biomarker in a large cohort of breast cancer patients. We correlated the expression of SALL4 in 160 cases of breast invasive ductal carcinoma, the most common histological type of breast cancer.

\section{Patients and methods}

Tissues and patients. 160 cases of breast cancer patients (median age, 51.0 years old; range, 29-83 years old) were recruited after randomization from January 2002 to October 2002. The specimens of carcinoma and matched adjacent noncancerous tissues were obtained immediately after tumor resections. All cases were examined pathologically to confirm the diagnosis of breast cancer, with the histological type of invasive ductal carcinoma. The carcinomas were evaluated by using the American Joint Committee on Cancer (AJCC), 7 th edition, staging system. None of the patients had received chemotherapy or radiotherapy before surgery. All patients in the series underwent surgery, including radical mastectomy, modified radical mastectomy or dissection, from January 2002 to November 2002 with a follow up of 12 years after surgery (Overall survival was defined as the time from diagnosis to the date of death or when censused at the latest date if patients were still alive). Of the 160 breast cancer patients, 51 patients were censused as death during the 12 years of follow-up time. Patients with perioperative death were excluded from this study. The study was approved by the Research Ethics Committee of our hospital.

Immunohistochemical analysis and evaluation. Immunohistochemical analysis was employed to study the altered protein expression in 160 human breast invasive ductal carcinoma tissues and matched adjacent noncancerous tissues. The formalin-fixed, paraffin- embedded sections ( $5 \mathrm{~mm}$ thickness) were deparaffinized in xylene and rehydrated in a graded series of ethanol solutions. The sections were subsequently submerged into EDTA ( $\mathrm{pH} 8$ ) and autoclave for 8 minutes (with temperature of $121 \otimes$ for the last 2 minutes) to retrieve the antigenicity. Endogenous peroxidase was quenched with $3 \% \mathrm{H}_{2} \mathrm{O}_{2}$ for 15 minutes. After washing with phosphate buffer solution (PBS), the sections were incubated with the primary antibody of SALL4 (1:1500; Abcam, ab29112), overnight at 48区. The sections were incubated with peroxidase-conjugated streptavidin for $30 \mathrm{~min}$ and the reaction products were visualized with diaminoben-zidine as a chromogen and counterstained with commercial hematoxylin. Negative controls were obtained by omitting the primary antibodies.

The brown granules in cytoplasm and nucleus were considered as staining of SALL4. Interestingly, SALL4 was predominantly observed in the cytoplasm with a diffuse distribution in the nucleus in both cancer and adjacent noncancerous tissues. In immunohistochemistry study, we focused on the cytoplasm staining of SALL4 instead of nuclear staining. For the assessment of immunostaining, the staining intensity was scored as follows $[18,19]$ : negative (score 0$)$, bordering (score 1), weak (score 2), moderate (score 3) and strong (score 4). Staining extent was graded into five parts according to the percentage of elevated staining cells in the field: negative (score 0), 0-25\% (score 1), 26-50\% (score 2), $51-75 \%$ (score 3 ) and $76-100 \%$ (score 4). Cytoplasmic SALL4 expression was evaluated by multiplying the scores of staining intensity and extent. The merged overall score was subjected to further survival analysis. Immunohistochemical staining was assessed and scored by two independent pathologists (Jingshu Geng and Xiaoming Ning) who were blinded to the clinicopathological data. Their conclusions were in complete agreement in $86 \%(138 / 160)$ of the cases, suggesting that the scoring system was highly reproducible. If both of the pathologists agreed with the results they scored, the value was selected. If the results were completely different, two pathologists worked together to confirm the final score.

Statistical analysis. All statistical analyses were performed by using the SPSS software version 21.0. Differences were considered statistically significant when $p$ values were $\leq 0.05$. For survival analysis, optimal cutoff point for SALL4 expression was obtained by receiver operating characteristic (ROC) analysis. Correlation between expression levels was studied by using the chi-square test or Fisher's exact test. Cumulative overall survival (OS) curves were plotted by the Kaplan- Meier method and the relationship between each of the variables and survival was assessed by log-rank test in a univariate analysis. The parameters were then tested by multivariate Cox proportional hazards model, which was performed to identify independent variables for predicting survival.

\section{Results}

Expression of SALL4 in human breast invasive ductal carcinoma and adjacent noncancerous tissues. Immunohistochemical analysis was employed to analyze the expression of SALL4 in breast invasive ductal carcinoma tissues compared with adjacent noncancerous tissues. As shown, SALL4 protein was found to be overexpressed in breast invasive ductal carcinoma tissues (Fig. $1 \mathrm{~A} 1$ and A2). Low or undetectable expression of SALL4 was observed in adjacent noncancerous tissues (Fig. 1 B1 and B2). To further assess survival analysis 

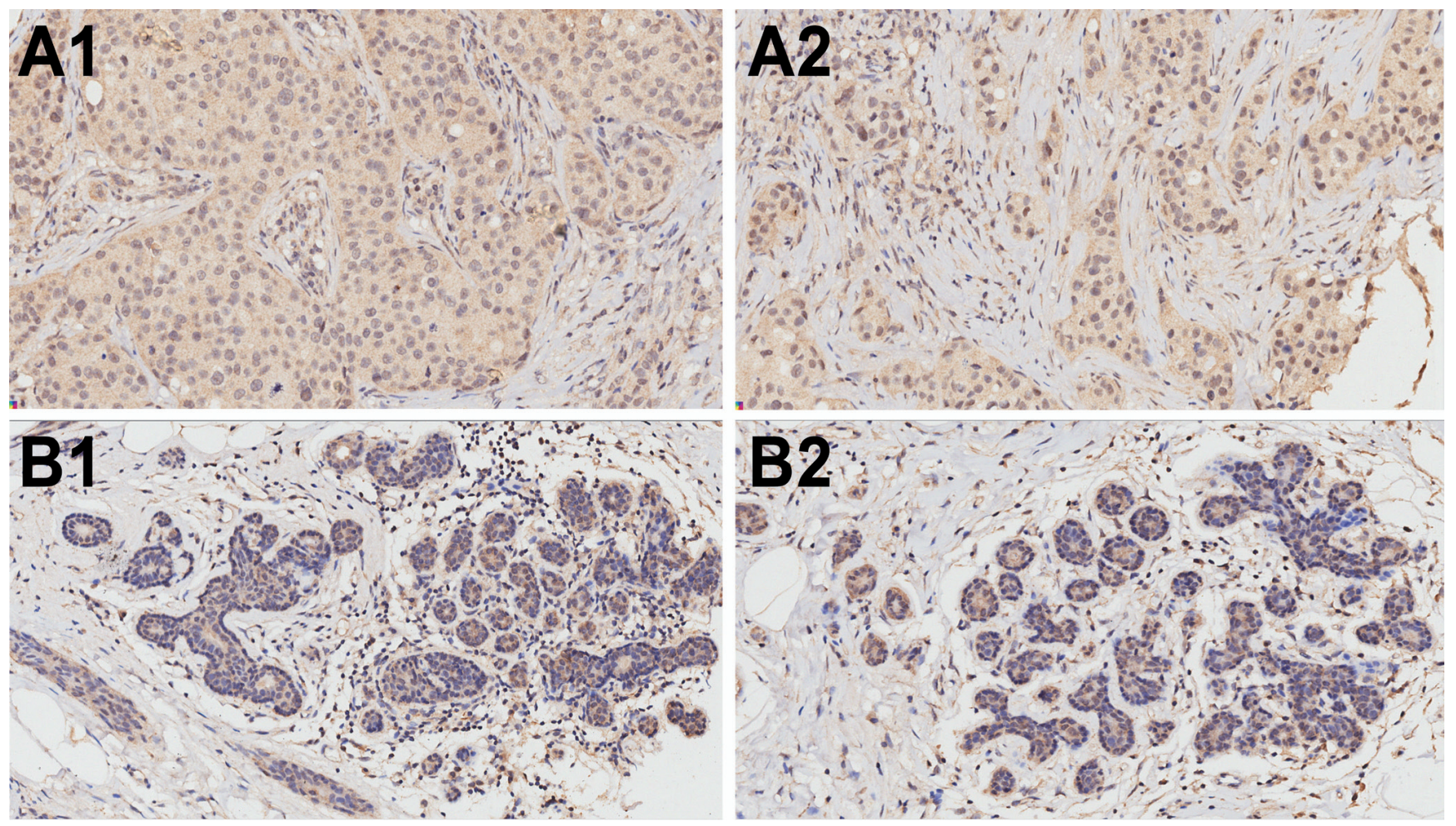

Figure 1. Immunohistochemical staining for SALL4 in breast invasive ductal carcinoma tissues and adjacent noncancerous tissues. (A1 and A2) SALL4 was overexpressed in breast invasive ductal carcinoma tissues $(400 \times)$. The staining of SALL4 was predominantly observed in the cytoplasm with a diffuse distribution in the nucleus in breast invasive ductal carcinoma cells. (B1 and B2) SALL4 was moderately expressed in adjacent noncancerous tissues (400×). High SALL4 expression cases exhibited cytoplasmic signal accompanied by dispersed nuclear staining.

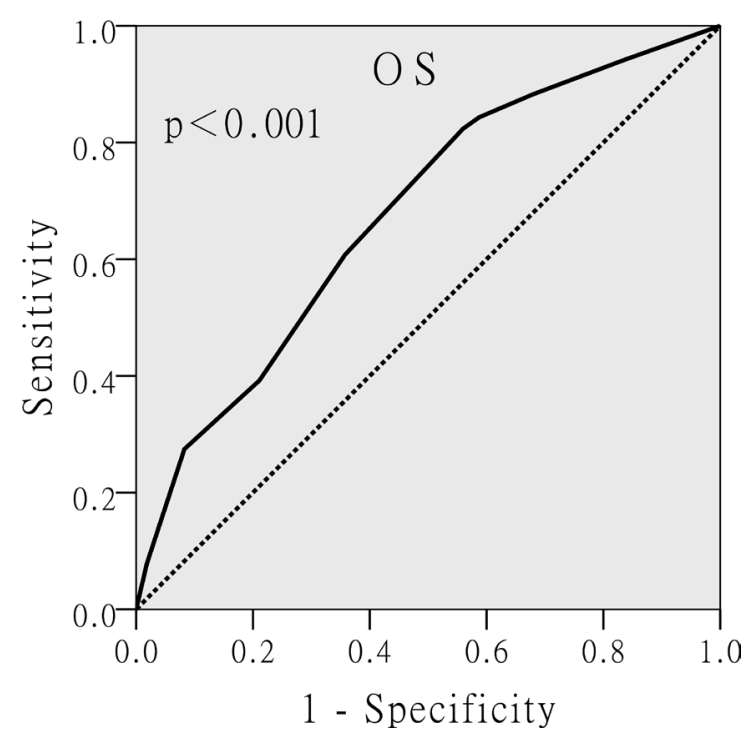

Figure 2. Receiver operating characteristic (ROC) curves analysis of SALLA cutoff score in overall patients. SALL4 cutoff point for overall survival in breast invasive ductal carcinoma patients. At each immunohistochemical score, the sensitivity and specificity for the outcome being studied were plotted, thus generating a ROC curve. Area under the curve (AUC) for SALL4 expression score was as large as 0.677 , whose $95 \%$ confidence interval ranged from 0.589 to $0.765, \mathrm{p}<0.001$. SALL4 cutoff score for overall survival was 5 . and avoid the problems of multiple cutoff point selection, ROC curve analysis was employed to determine a cutoff score for cytoplasmic SALL4 expression in overall patients. As shown in Figure 2, the SALL4 cutoff score for OS in overall patients $(\mathrm{n}=160)$ was $5(\mathrm{p}<0.001)$. We thus selected a cytoplasmic SALL4 expression score of 5 ( $>5$ denoted as high expression vs. $\leq 5$ denoted as low expression) as the uniform cutoff point for survival analysis. With the cytoplasmic SALL4 expression score of 5 defined as the cutoff point, the high expression rate of SALL4 was $64.4 \%$ in breast cancer tissues ( $n=160$, Fig. 1A) and $35.6 \%$ in adjacent noncancerous tissues $(n=160$, Fig. 1B) respectively (Figure 3, $\mathrm{p}<0.001$ ).

SALL4 expression and clinical features. ROC-derived SALL4 cutoff score of 5 segregated overall patients into high $(103 / 160,64.4 \%)$ and low $(57 / 160,35.6 \%)$ subgroups. As shown in Table 1, high expression of SALL4 was mostly found in poorly differentiated breast invasive ductal carcinoma tissues $(27 / 35,77.1 \%$, in Grade 3 vs. $48 / 70,68.6 \%$, in G2 vs. $28 / 55$, $50.9 \%$, in $\mathrm{G} 1, \mathrm{p}=0.025)$. Further correlation analysis demonstrated that SALL4 was significantly positively associated with AJCC stage ( $\mathrm{p}=0.008$, Table 1$)$. In addition, high cytoplasmic SALL4 expression is associated with advanced tumor invasion $(\mathrm{p}=0.019$, Table 1$)$, lymph node stage $(\mathrm{p}=0.027$, Table 1$)$, ER status $(p=0.030$, Table 1$)$, PR status $(p=0.037$, Table 1$)$, 
Table 1. Association of SALL4 expression with patients' characteristics in breast invasive ductal carcinoma

\begin{tabular}{|c|c|c|c|c|c|}
\hline \multirow{2}{*}{ Variables } & \multirow{2}{*}{ No.(160) } & \multicolumn{3}{|c|}{ SALL4 } & \multirow{2}{*}{$\mathrm{p}$} \\
\hline & & High group & Low group & $\%$ & \\
\hline Age (years) & & & & & 0.819 \\
\hline$<40$ & 27 & 17 & 10 & 62.96 & \\
\hline $40-60$ & 86 & 54 & 32 & 62.79 & \\
\hline$>60$ & 47 & 32 & 15 & 68.09 & \\
\hline Family history of tumor & & & & & 0.07 \\
\hline Yes & 40 & 21 & 19 & 52.50 & \\
\hline No & 120 & 82 & 38 & 68.33 & \\
\hline Differentiation grade & & & & & 0.025 \\
\hline G 1 & 55 & 28 & 27 & 50.91 & \\
\hline G 2 & 70 & 48 & 22 & 68.57 & \\
\hline G 3 & 35 & 27 & 8 & 77.14 & \\
\hline pT classification & & & & & 0.019 \\
\hline $\mathrm{T} 1$ & 37 & 17 & 20 & 45.95 & \\
\hline $\mathrm{T} 2$ & 108 & 74 & 34 & 68.52 & \\
\hline $\mathrm{T} 3$ & 15 & 12 & 3 & 80.00 & \\
\hline pN classification & & & & & 0.027 \\
\hline N0, N1 & 115 & 68 & 47 & 59.13 & \\
\hline $\mathrm{N} 2, \mathrm{~N} 3$ & 45 & 35 & 10 & 77.78 & \\
\hline AJCC stage & & & & & 0.008 \\
\hline I & 16 & 5 & 11 & 31.25 & \\
\hline II & 94 & 61 & 33 & 64.89 & \\
\hline III & 50 & 37 & 13 & 74.00 & \\
\hline Estrogen receptor & & & & & 0.03 \\
\hline Positive & 103 & 60 & 43 & 58.25 & \\
\hline Negative & 57 & 43 & 14 & 75.44 & \\
\hline Progesterone receptor & & & & & 0.037 \\
\hline Positive & 89 & 51 & 38 & 57.30 & \\
\hline Negative & 71 & 52 & 19 & 73.24 & \\
\hline Human epidermal growth factor receptor 2 & & & & & 0.019 \\
\hline Positive & 49 & 25 & 24 & 51.02 & \\
\hline Negative & 111 & 78 & 33 & 70.27 & \\
\hline Cancer subtype & & & & & 0.007 \\
\hline TNBC & 29 & 25 & 4 & 86.21 & \\
\hline non-TNBC & 131 & 78 & 53 & 59.54 & \\
\hline
\end{tabular}

HER2 status ( $\mathrm{p}=0.019$, Table 1$)$ and cancer subtype (TNBC vs. non-TNBC) $(\mathrm{p}=0.007$, Table 1$)$ in overall patient. We failed to detect that SALL4 was correlated with other patients' characteristics, including age and tumor family history.

SALL4 expression and survival analysis: Univariate survival analysis. Kaplan-Meier analysis showed that high expression of SALL4 strongly predicted an inferior OS in overall patients ( $\mathrm{p}<0.001$ for OS, Fig. $4 \mathrm{~A})$. Further analysis was performed with regard to cytoplasmic SALL4 expression in subsets of breast cancer patients within each clinical stage (stage I was not included due to few patients). The results demonstrated that high cytoplasmic expression of SALL4 could be supposed as a poor prognostic factor in each stage of breast cancer patients: stage II ( $\mathrm{p}=0.036$ for OS, Fig. $4 \mathrm{~B}$ ) and stage III ( $\mathrm{p}=0.038$ for OS, Fig. $4 \mathrm{C}$ ). In univariate Cox regression models, tumor differentiation grade $(\mathrm{p}=0.001)$, tumor invasion $(p=0.011)$, lymph node stage $(p=0.001)$, AJCC stage $(\mathrm{p}=0.003)$, ER status $(\mathrm{p}=0.024)$, PR status $(\mathrm{p}=$ $0.024)$, HER2 status $(\mathrm{p}=0.023)$, cancer subtype (TNBC vs. non-TNBC) $(\mathrm{p}<0.001)$ and SALL4 $(\mathrm{p}=0.001)$ were found to achieve statistical significance (Table 2).

Multivariate Cox regression analysis. The cytoplasmic expression of SALL4 as well as other parameters were examined in multivariate Cox analysis (Table 2). SALL4 was indeed found to be a significant independent prognostic factor for OS (hazard ratio, 0.417; 95\% CI, 0.189-0.921; $\mathrm{p}=0.030$; Table 2). Moreover, histology differentiation was also identified as an independent prognostic parameter for OS in overall patients (Table 2). Of other parameters, cancer subtype (TNBC vs. non-TNBC) was evaluated as an independent prognostic fac- 


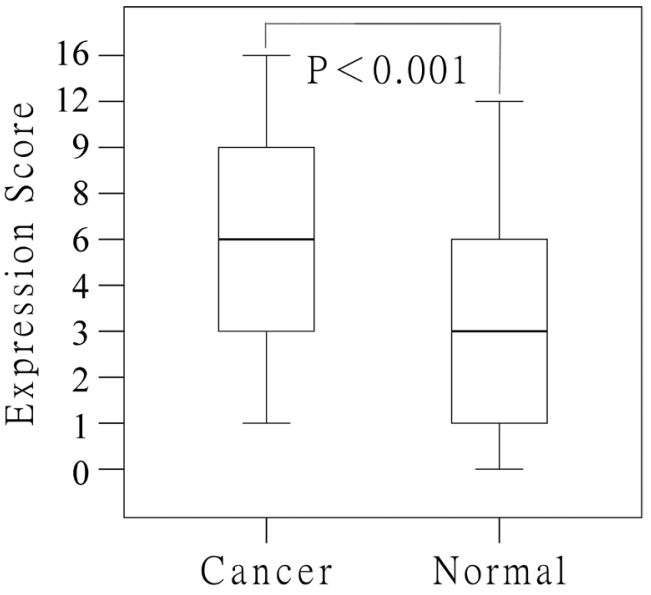

SALL4

Figure 3. Immunohistochemical analysis of proteins expression in breast invasive ductal carcinoma tissues $(n=160)$ and adjacent noncancerous tissues $(n=160)$. Compared with the adjacent noncancerous tissues, breast cancer tissues expressed significantly high SALL4 $(\mathrm{P}<0.0001)$.

tor for OS in overall patients (Table 2). However, we failed to detect that other factors, including age, family history of tumor, tumor invasion, lymph node stage, AJCC stage, ER status, PR status and HER2 status, were independent prognostic factors for breast cancer, implying that a larger number of cases might be needed in future studies.

\section{Discussion}

SALL4, belonging to SALL gene family and acting as a zincfinger transcriptional factor, has been suggested to be involved in tumorigenesis and identified as a novel prognostic biomarker for some tumors. SALL4 was reported to be involved in three signaling pathways, associating with self-renewal and differentiation, including PTEN [20], Wnt/beta-catenin [10] and Bmi-1 $[21,22]$. SALL4 was also supposed to sustain the stemness of embryonic stem cells through establishing a regulatory signal transmission network with Sox2, Nanog and Oct4 [7, 9, 23-26]. These previous researches have revealed that SALL4 plays a significant role in preserving the pluripotency, self-renewal and even decision of cell fate in embryonic stem cells $[6,23-25,27]$. SALL4 has been demonstrated to be involved in normal hematopoiesis. The dysfunction of SALL4 signaling was connected with leukemogenesis. SALL4 was discovered to be expressed in and also lead to acute myeloid leukemia highly possible through the signaling pathway of Wnt/beta-catenin [10].In addition, a novel association between SALL4 and Bmi-1 was found in adjusting self-renewal and pluripotency of normal and leukemic stem cells [21]. Furthermore, the anomalous expression of SALL4 has also been investigated in solid tumors. SALL4, as a specific and sensitive marker, has been proved to be beneficial in screening out metastatic germ cell tumors, especially metastatic yolk sac tumors [11]. SALL4 was demonstrated to play an oncogenic role in gastric cancer by modulating cell stemness and epithelial-mesenchymal transition and supposed to be a new target for diagnosis and therapy for human gastric cancer [15]. The over expression of SALL4 has been observed in human liver cancer [28]. SALL4 was also considered as a marker for an aggressive phenotype of liver cancer in a progenitor subclass, and most likely a novel target with therapeutic purpose for hepatocellular carcinoma [12]. However, when it comes to the expression of SALL4 in breast cancer, very few studies have been focused on. The levels of SALL4 mRNA were detected to rise up to $86.1 \%(31 / 36)$ in early-stage breast cancer tissue samples [16]. In cell culture and behavior analyses, SALL4 was characterized as a dispersion factor by suppressing adhesion gene $\mathrm{CDH} 1$ expression and maintaining the dispersion status of basal-like breast cancer [17]. The expression dynamics of SALL4 and its prognostic significance in breast cancer remain widely unknown.

In the present study, the expression pattern of SALL4 has been detected in breast invasive ductal carcinoma and adjacent noncancerous tissues. The staining of SALL4 was

Table 2. Results of univariate and multivariate Cox proportional-hazards analysis in overall patients

\begin{tabular}{|c|c|c|c|c|c|c|c|c|c|c|}
\hline \multirow{3}{*}{$\begin{array}{l}\text { Variable } \\
\text { Age }\end{array}$} & \multicolumn{5}{|c|}{ Univariate for death } & \multicolumn{5}{|c|}{ Multivariate for death } \\
\hline & \multirow{2}{*}{$\frac{\text { Risk ratio }}{1.338}$} & \multicolumn{2}{|c|}{$95 \% \mathrm{CI}$} & & \multirow{2}{*}{$\frac{\mathrm{p}}{0.178}$} & \multirow{2}{*}{$\begin{array}{c}\text { Risk ratio } \\
1.148\end{array}$} & \multicolumn{2}{|c|}{$95 \% \mathrm{CI}$} & \multirow{2}{*}{\multicolumn{2}{|c|}{$\frac{p}{0.526}$}} \\
\hline & & $(0.876$ &,$\quad 2.043$ & ) & & & $(0.749$ & , 1.759 & & \\
\hline Family history of tumor & 0.812 & $(0.417$ & , $\quad 1.584$ & ) & 0.542 & 0.786 & $(0.381$ & , 1.620 & ) & 0.513 \\
\hline Differentiation grade & 3.447 & $(1.656$ &,$\quad 7.175$ & ) & 0.001 & 1.648 & $(1.036$ & , 2.622 & ) & 0.035 \\
\hline Tumor invasion & 2.080 & $(1.179$ &,$\quad 3.670$ & ) & 0.011 & 0.738 & $(0.265$ & , 2.057 & ) & 0.562 \\
\hline Lymph node stage & 2.561 & $(1.474$ &,$\quad 4.450$ & ) & 0.001 & 0.732 & $(0.092$ & , 5.846 & ) & 0.769 \\
\hline AJCC stage & 2.323 & $(1.340$ &,$\quad 4.027$ & ) & 0.003 & 0.598 & $(0.059$ & , 6.053 & ) & 0.663 \\
\hline Estrogen receptor & 0.531 & $(0.306$ & , $\quad 0.920$ & ) & 0.024 & 0.215 & $(0.045$ & , 1.016 & ) & 0.052 \\
\hline Progesterone receptor & 0.527 & $(0.302$ &,$\quad 0.917$ & ) & 0.024 & 0.669 & $(0.270$ & , 1.659 & ) & 0.386 \\
\hline $\begin{array}{l}\text { Human epidermal } \\
\text { growth factor receptor } 2\end{array}$ & 0.433 & $(0.211$ & , $\quad 0.891$ & ) & 0.023 & 0.792 & $(0.336$ & , 1.865 & ) & 0.594 \\
\hline Triple-negative breast cancer & 6.593 & ( 3.699 & , 11.750 & ) & $<0.001$ & 0.033 & $(0.006$ & , 0.188 & ) & $<0.001$ \\
\hline SALL4 & 3.447 & $(1.656$ & , 7.175 & ) & 0.001 & 0.417 & $(0.189$ & , 0.921 & ) & 0.030 \\
\hline
\end{tabular}



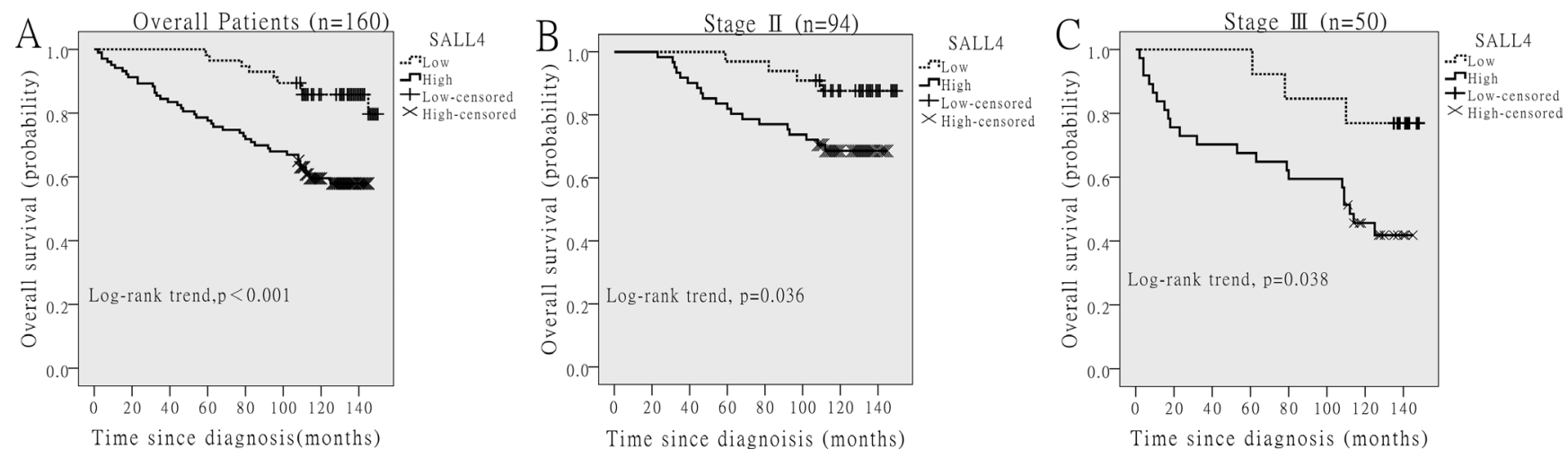

Figure 4. Kaplan-Meier survival analysis of SALL4 expression in breast invasive ductal carcinoma patients. (A) Probability of OS in breast cancer patients with all stages: high expression, $n=103$; low expression, $n=57$. High expression of SALL4 was closely correlated with poor OS in overall patients (chi-square statistic $=12.355, p<0.001)$. (B) Probability of OS in breast cancer patients with AJCC stage II: high expression, $n=61 ;$ low expression, $n=$ 33. High expression of SALL4 acquired an inferior OS in patients with AJCC stage II (chi-square statistic $=4.390, p=0.036$ ). (C) Probability of OS in breast cancer patients with AJCC stage III: high expression, $n=37$; low expression, $n=13$. High expression of SALL4 was also associated with a poor OS in patients with AJCC stage III (chi-square statistic $=4.320, \mathrm{p}=0.038$ ).

mainly found in the cytoplasm with a diffuse distribution in the nucleus. The result of predominantly cytoplasmic staining of SALL4 was dissimilar with most studies of SALL4 in other carcinomas which observed largely nuclear staining of SALL4 $[15,29,30]$. Under some circumstances, some kinds of transcription factors may be located in the cytoplasm prior to activation, and become relocated in the nucleus in response to the appropriate signal [31]. We hypothesize that SALL4, as a transcription factor, may be able to shuttle between nucleus and cytoplasm, which needs to be further verified by more studies. With similarity to the results in previous studies $[29,32]$, the expression level of SALL4, correlating tightly with cancer differentiation, was found to be higher in cancer tissues with poor differentiation (Fig. 1; Table 1). In addition, SALL4 was further confirmed as an independent biomarker with prognostic value for OS in overall patients (Fig. 4; Tables 2). Simultaneously, inferior prognostic influence of high SALL4 expression was also displayed in breast cancer patients among each clinical stage(Fig. 4), suggesting that detection of SALL4 expressing status could be validated to be an extra efficient tool in sorting out those breast invasive ductal carcinoma patients with higher risk of tumor recurrence and progression. As a result of the limitation of the data of triple-negative breast cancer patients involved in our study, a precise prognostic value of the SALL4 expression remains uncertain for this significant subtype of breast cancer and much more studies are nevertheless needed. To sum up, our discoveries in this research presented evidence that elevated cytoplasmic SALL4 expression might indicate a phenotype of breast cancer with increased risk of malignance and worse prognosis. With no other histological type, such as invasive lobular carcinoma, involved in our research, a larger cohort of clinicopathological study on the prognostic value of SALL4 in breast cancer is still of utmost necessity.
SALL4 administers the survival of cells through aiming at a series of genes involved in pro-apoptotic and anti-apoptotic signaling pathways [33]. In addition, the expression of this kind of genes is administered by SALL4 in embryonic stem cells [9]. In breast cancer cells, the overexpression of SALL4 might play an essential role in sustaining the survival of tumor cell by transcriptionally repressing genes in pro-apoptotic pathways, such as PTEN. Coincidently, the expression level of PTEN in breast cancer tissues was lower or negative compared with matched adjacent noncancerous tissues [34-36]. The reason for deficient expression of PTEN protein in breast cancer tissues could be determined by varied mutations of the PTEN gene. On the basis of our findings, we hypothesize that overexpression of SALL4 probably plays a novel role in repressing the transcript of PTEN and contributing to down-regulation of PTEN in breast cancer cells. First of all, down-regulation of SALL4 could lead to apoptosis [22], possible through activating some genes, such as PTEN, which are in pro-apoptotic pathway. It has been found that, by targeting and adjusting a series of genes involved in signaling pathways of both pro- and anti-apoptosis, SALL4 regulates cell survival in human acute promyelocytic leukemia cells [22]. Additionally, PTEN was regarded as one of the most significant tumor-suppressing genes which have close association with breast cancer risks [37, 38]. Thus, overexpression of SALL4 might regulate cells survival of breast cancer by restraining the process of apoptosis through inhibiting PTEN transcription. What's more, PTEN restrains the PI3K/AKT/mTOR signaling pathway through splitting a phosphate group from the second messenger PIP-3 activated by PI3K [39-41]. It is our hypothesis that SALL4 might play a role in the PI3K/AKT/ mTOR pathway by tightly connecting with PTEN. Interestingly, the initiation of process of autophagy is partly regulated through the PI3K/AKT/mTOR pathway [42]. Therefore, we also hypothesize that SALL4 might have a close association 
with autophagy through regulating the $\mathrm{PI} 3 \mathrm{~K} / \mathrm{AKT} / \mathrm{mTOR}$ pathway, which needs to be proved further by more in vitro and in vivo studies.

In conclusion, our research suggested that SALL4 served as an independent marker with prognostic value and even a therapeutic target for patient survival in breast invasive ductal carcinoma and the cytoplasmic expression of SALL4 could be of help in determining the outcome of patients with breast cancer in clinical practice. Our data demonstrate a novel understanding of the connection between SALL4 and tumor differentiation in tumor progression and may shed light on the illustration of tumor pathophysiology of breast cancer.

Acknowledgements: This study was supported by the Affiliated Tumor Hospital of Harbin Medical University, the Institute of Cancer Prevention and Treatment of Harbin Medical University and the Fourth Affiliated Hospital of Harbin Medical University. The authors wish to thank the anonymous reviewers for their invaluable suggestions that helped to improve the manuscript. We also sincerely thank Dr. Mingming Zhang (the College of Bioinformatics Science and Technology, Harbin Medical University) for her selfless work in experimental design and statistical consultation.

\section{References}

[1] BENSON JR, JATOI I, KEISCH M, ESTEVA FJ, MAKRIS A et al. Early breast cancer. Lancet 2009; 373: 1463-1479. http:// dx.doi.org/10.1016/S0140-6736(09)60316-0

[2] DESANTIS C, MA J, BRYAN L, JEMAL A. Breast cancer statistics, 2013. CA Cancer J Clin 2014; 64: 52-62. http://dx.doi. org/10.3322/caac. 21203

[3] VERMA R, BOWEN RL, SLATER SE, MIHAIMEED F, JONES JL. Pathological and epidemiological factors associated with advanced stage at diagnosis of breast cancer. Br Med Bull 2012; 103: 129-145. http://dx.doi.org/10.1093/bmb/lds018

[4] IWASAKI M, TSUGANE S. Risk factors for breast cancer: epidemiological evidence from Japanese studies. Cancer Sci 2011; 102: 1607-1614. http://dx.doi.org/10.1111/j.1349-7006 .2011.01996.x

[5] DE CELIS JF, BARRIO R. Regulation and function of Spalt proteins during animal development. Int J Dev Biol 2009; 53: 1385-1398. http://dx.doi.org/10.1387/ijdb.072408jd

[6] ELLING U, KLASEN C, EISENBERGER T, ANLAG K, TREIER M. Murine inner cell mass-derived lineages depend on Sall4 function. Proc Natl Acad Sci U S A 2006; 103: 16319-16324. http://dx.doi.org/10.1073/pnas.0607884103

[7] YANG J, GAO C, CHAI L, MA Y. A novel SALL4/OCT4 transcriptional feedback network for pluripotency of embryonic stem cells. PLoS One 2010; 5: e10766. http://dx.doi. org/10.1371/journal.pone.0010766

[8] RAO S, ZHEN S, ROUMIANTSEV S, MCDONALD LT, YUAN GC et al. Differential roles of Sall4 isoforms in embryonic stem cell pluripotency. Mol Cell Biol 2010; 30: 5364-5380. http://dx.doi.org/10.1128/MCB.00419-10

[9] LIM CY, TAM WL, ZHANG J, ANG HS, JIA H et al. Sall4 regulates distinct transcription circuitries in different blastocyst-derived stem cell lineages. Cell Stem Cell 2008; 3: 543-554. http://dx.doi.org/10.1016/j.stem.2008.08.004

[10] MA Y, CUI W, YANG J, QU J, DI C et al. SALL4, a novel oncogene, is constitutively expressed in human acute myeloid leukemia (AML) and induces AML in transgenic mice. Blood 2006; 108: 2726-2735. http://dx.doi.org/10.1182/blood-2006 $-02-001594$

[11] CAO D, HUMPHREY PA, ALLAN RW. SALL4 is a novel sensitive and specific marker for metastatic germ cell tumors, with particular utility in detection of metastatic yolk sac tumors. Cancer 2009; 115: 2640-2651. http://dx.doi. org/10.1002/cncr.24308

[12] YONG KJ, GAO C, LIM JS, YAN B, YANG H et al. Oncofetal gene SALL4 in aggressive hepatocellular carcinoma. N Engl J Med 2013; 368: 2266-2276. http://dx.doi.org/10.1056/NEJMoa1300297

[13] FORGHANIFARD MM, MOGHBELI M, RAEISOSSADATI $\mathrm{R}$, TAVASSOLI A, MALLAK AJ et al. Role of SALL4 in the progression and metastasis of colorectal cancer. J Biomed Sci 2013; 20: 6. http://dx.doi.org/10.1186/1423-0127-20-6

[14] WANG F, LIU A, PENG Y, RAKHEJA D, WEI L et al. Diagnostic utility of SALL4 in extragonadal yolk sac tumors: an immunohistochemical study of 59 cases with comparison to placental-like alkaline phosphatase, alpha-fetoprotein, and glypican-3. Am J Surg Pathol 2009; 33: 1529-1539. http:// dx.doi.org/10.1097/PAS.0b013e3181ad25d5

[15] ZHANG L, XU Z, XU X, ZHANG B, WU H et al. SALL4, a novel marker for human gastric carcinogenesis and metastasis. Oncogene 2013.

[16] KOBAYASHI D, KURIBAYSHI K, TANAKA M, WATANABE N. SALL4 is essential for cancer cell proliferation and is overexpressed at early clinical stages in breast cancer. Int J Oncol 2011; 38: 933-939.

[17] ITOU J, MATSUMOTO Y, YOSHIKAWA K, TOI M. Sal-like 4 (SALL4) suppresses CDH1 expression and maintains cell dispersion in basal-like breast cancer. FEBS Lett 2013; 587: 3115-3121. http://dx.doi.org/10.1016/j. febslet.2013.07.049

[18] WAN XB, FAN XJ, CHEN MY, XIANG J, HUANG PY et al. Elevated Beclin 1 expression is correlated with HIF-1alpha in predicting poor prognosis of nasopharyngeal carcinoma. Autophagy 2010; 6: 395-404. http://dx.doi.org/10.4161/ auto.6.3.11303

[19] ZHOU WH, TANG F, XU J, WU X, YANG SB et al. Low expression of Beclin 1, associated with high $\mathrm{Bcl}-\mathrm{xL}$, predicts a malignant phenotype and poor prognosis of gastric cancer. Autophagy 2012; 8: 389-400. http://dx.doi.org/10.4161/auto. 18641

[20] LU J, JEONG HW, KONG N, YANG Y, CARROLL J et al. Stem cell factor SALL4 represses the transcriptions of PTEN and SALL1 through an epigenetic repressor complex. PLoS One 2009; 4: e5577. http://dx.doi.org/10.1371/journal. pone. 0005577

[21] YANG J, CHAI L, LIU F, FINK LM, LIN P et al. Bmi-1 is a target gene for SALL4 in hematopoietic and leukemic cells. Proc Natl Acad Sci U S A 2007; 104: 10494-10499. http:// dx.doi.org/10.1073/pnas.0704001104 
[22] YANG J, CHAI L, GAO C, FOWLES TC, ALIPIO Z et al. SALL4 is a key regulator of survival and apoptosis in human leukemic cells. Blood 2008; 112: 805-813. http://dx.doi. org/10.1182/blood-2007-11-126326

[23] WANG J, RAO S, CHU J, SHEN X, LEVASSEUR DN et al. A protein interaction network for pluripotency of embryonic stem cells. Nature 2006; 444: 364-368. http://dx.doi. org/10.1038/nature05284

[24] ZHANG J, TAM WL, TONG GQ, WU Q, CHAN HY et al. Sall4 modulates embryonic stem cell pluripotency and early embryonic development by the transcriptional regulation of Pou5f1. Nat Cell Biol 2006; 8: 1114-1123. http://dx.doi. org/10.1038/ncb1481

[25] WU Q, CHEN X, ZHANG J, LOH YH, LOW TY et al. Sall4 interacts with Nanog and co-occupies Nanog genomic sites in embryonic stem cells. J Biol Chem 2006; 281: 24090-24094. http://dx.doi.org/10.1074/jbc.C600122200

[26] ZHOU Q, CHIPPERFIELD H, MELTON DA, WONG WH. A gene regulatory network in mouse embryonic stem cells. Proc Natl Acad Sci U S A 2007; 104: 16438-16443. http:// dx.doi.org/10.1073/pnas.0701014104

[27] WARREN M, WANG W, SPIDEN S, CHEN-MURCHIE D, TANNAHILL D et al. A Sall4 mutant mouse model useful for studying the role of Sall4 in early embryonic development and organogenesis. Genesis 2007; 45: 51-58. http://dx.doi. org/10.1002/dvg.20264

[28] OIKAWA T, KAMIYA A, ZENIYA M, CHIKADA H, HYUCK AD et al. Sal-like protein 4 (SALL4), a stem cell biomarker in liver cancers. Hepatology 2013; 57: 1469-1483. http://dx.doi. org/10.1002/hep.26159

[29] RODRIGUEZ E, CHEN L, AO MH, GEDDES S, GABRIELSON E et al. Expression of transcript factors SALL4 and OCT4 in a subset of non-small cell lung carcinomas (NSCLC). Transl Respir Med 2014; 2: 10. http://dx.doi.org/10.1186/s40247-014 $-0010-7$

[30] GONZALEZ-ROIBON N, KATZ B, CHAUX A, SHARMA R, MUNARI E et al. Immunohistochemical expression of SALL4 in hepatocellular carcinoma, a potential pitfall in the differential diagnosis of yolk sac tumors. Hum Pathol 2013; 44: 1293-1299. http://dx.doi.org/10.1016/j.humpath.2012.10.017

[31] WHITESIDE ST, GOODBOURN S. Signal transduction and nuclear targeting: regulation of transcription factor activity by subcellular localisation. J Cell Sci 1993; 104 (Pt 4): 949-955.

[32] ARDALAN KHALES S, ABBASZADEGAN MR, ABDOLLAHI A, RAEISOSSADATI R, TOUSI MF et al. SALL4 as a new biomarker for early colorectal cancers. J Cancer Res Clin Oncol 2015; 141: 229-235. http://dx.doi.org/10.1007/ s00432-014-1808-y

[33] GUO Y, MANTEL C, HROMAS RA, BROXMEYER HE. Oct-4 is critical for survival/antiapoptosis of murine embryonic stem cells subjected to stress: effects associated with Stat3/survivin. Stem Cells 2008; 26: 30-34. http://dx.doi. org/10.1634/stemcells.2007-0401

[34] LEE JS, KIM HS, KIM YB, LEE MC, PARK CS et al. Reduced PTEN expression is associated with poor outcome and angiogenesis in invasive ductal carcinoma of the breast. Appl Immunohistochem Mol Morphol 2004; 12: 205-210. http:// dx.doi.org/10.1097/00129039-200409000-00004

[35] CHUNG MJ, JUNG SH, LEE BJ, KANG MJ, LEE DG. Inactivation of the PTEN gene protein product is associated with the invasiveness and metastasis, but not angiogenesis, of breast cancer. Pathol Int 2004; 54: 10-15. http://dx.doi. org/10.1111/j.1440-1827.2004.01576.x

[36] DEPOWSKI PL, ROSENTHAL SI, ROSS JS. Loss of expression of the PTEN gene protein product is associated with poor outcome in breast cancer. Mod Pathol 2001; 14: 672-676. http://dx.doi.org/10.1038/modpathol.3880371

[37] MAHDI KM, NASSIRI MR, NASIRI K. Hereditary genes and SNPs associated with breast cancer. Asian Pac J Cancer Prev 2013; 14: 3403-3409. http://dx.doi.org/10.7314/ APJCP.2013.14.6.3403

[38] WENG LP, SMITH WM, DAHIA PL, ZIEBOLD U, GIL E et al. PTEN suppresses breast cancer cell growth by phosphatase activity-dependent G1 arrest followed by cell death. Cancer Res 1999; 59: 5808-5814.

[39] LI J, YEN C, LIAW D, PODSYPANINA K, BOSE S et al. PTEN, a putative protein tyrosine phosphatase gene mutated in human brain, breast, and prostate cancer. Science 1997; 275: 1943-1947. http://dx.doi.org/10.1126/ science. 275.5308 .1943

[40] LI DM, SUN H. TEP1, encoded by a candidate tumor suppressor locus, is a novel protein tyrosine phosphatase regulated by transforming growth factor beta. Cancer Res 1997; 57: 2124-2129.

[41] VAZQUEZ F, SELLERS WR. The PTEN tumor suppressor protein: an antagonist of phosphoinositide 3-kinase signaling. Biochim Biophys Acta 2000; 1470: M21-35.

[42] LEVINE B, SINHA S, KROEMER G. Bcl-2 family members: dual regulators of apoptosis and autophagy. Autophagy 2008; 4: 600-606. http://dx.doi.org/10.4161/auto.6260 